\title{
A mineração extrativista em Minas Gerais: “ai, antes fosse mais leve a carga"
}

\author{
Kathiuça Bertollo ${ }^{1}$ \\ https://orcid.org/0000-0003-2394-383X \\ ${ }^{1}$ Universidade Federal de Ouro Preto, Departamento de Serviço Social, Curso de Serviço Social, Mariana, MG, Brasil
}

\begin{abstract}
A mineração extrativista em Minas Gerais: “ai, antes fosse mais leve a carga”
Resumo: A América Latina figura historicamente como um continente saqueado e explorado, bem como suas gentes e seus bens naturais comuns, pelos países de capitalismo central. No atual cenário de dominação imperialista, a mineração extrativista é reconhecida como uma imprescindível atividade produtiva do capitalismo mundializado e do padrão exportador em vigência no continente latino-americano. Diante disso, este artigo busca explicitar e refletir sobre o contexto da mineração extrativista de minério de ferro em Minas Gerais, mais especificamente na região do quadrilátero ferrífero, dando ênfase aos recentes rompimentos criminosos das barragens de rejeitos, à superexploração da força de trabalho, à destruição ambiental e às resistências travadas pelas comunidades e populações direta e indiretamente atingidas e por demais sujeitos coletivos que assumem como pauta de luta o enfrentamento a esse modelo de mineração e às violências e violações que gera.
\end{abstract}

Palavras-chave: América Latina. Capitalismo dependente. Mineração extrativista. Quadrilátero ferrífero. Minas Gerais. Lutas sociais. Violência. Violações.

\section{The extractive mining in Minas Gerais: "ah, if the load was lighter"}

Abstract: Latin America figures historically as a continent plundered and exploited, with its people and natural resources, by countries of central capitalism. In the current context of imperialist domination, the extractive mining is recognized as an indispensable productive activity of the globalized capitalism and of the exporting business model that is in effect in the Latin American continent. In view of this context, this article aims to show and reflect upon the extractive mining of iron ore in Minas Gerais, more specifically in the region known as the "ferriferous quadrilateral", putting emphasis on the recent criminal bursts of tailings dams, on the super-exploitation of the workforce, on the environmental destruction and on the resistance put up by the communities and populations directly and indirectly affected as well as by other collective subjects that adopted as their cause the fight against the current model of mining and against the violence and violations that it entails. Keywords: Latin America. Dependent capitalism. Extractive mining. Ferriferous quadrilateral. Minas Gerais. Social fights. Violence. Violations.

Recebido em 23.02.2021. Aprovado em 16.05.2021. Revisado em 22.06.2021.

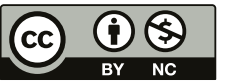

Este é um artigo publicado em acesso aberto (Open Access) sob a licença Creative Commons Attribution NonCommercial, que permite uso, distribuição e reprodução em qualquer meio, sem restrições desde que sem fins comerciais e que o trabalho original seja corretamente citado. 


\title{
Introdução
}

\author{
O Rio? É doce. \\ A Vale? Amarga. \\ Ai, antes fosse \\ Mais leve a carga. \\ (Carlos Drummond de Andrade)
}

Este artigo explicita e reflete sobre o contexto da mineração extrativista de minério de ferro em Minas Gerais (MG), mais especificamente na região do quadrilátero ferrífero ${ }^{1}$, dando ênfase aos recentes rompimentos criminosos das barragens de rejeitos, à superexploração da força de trabalho, à destruição ambiental e às resistências travadas pelas comunidades e populações direta e indiretamente atingidas e por demais sujeitos coletivos que assumem como pauta de luta o enfrentamento a esse modelo de mineração e às violências e violações que gera.

Para tanto, será refletido e problematizado acerca do lugar ocupado historicamente pela América Latina, dando ênfase à atual fase de conformação do capitalismo sob o domínio e hegemonia imperialista e a conformação do capitalismo dependente neste território, sobre suas gentes e bens naturais comuns.

O modelo extrativista exportador em voga na América Latina, e que abarca a mineração extrativista de minério de ferro em MG, sustenta-se na superexploração da força de trabalho e destruição ambiental. São consequências notórias dessa conformação os históricos e os recentes rompimentos/crimes da barragem de rejeitos, dentre os quais ganharam evidência mundial o da barragem de Fundão em Mariana (MG) no ano de 2015 e o da barragem de Córrego do Feijão em Brumadinho (MG) no ano de 2019. Esses fatos reafirmam a lógica dependente e subordinada no modo de produção capitalista e o perfil primário-exportador do País no contexto econômico mundial em que tal atividade produtiva e tal região de MG ocupam um lugar relevante.

Com o agravamento da exploração e destruição nas localidades atingidas direta e indiretamente pela mineração extrativista de minério de ferro, bem como pelos rompimentos das barragens de rejeitos, o contexto de luta e resistência historicamente desencadeado nesta região de $\mathrm{MG}$ se ampliou e se intensificou. Movimentos sociais, entidades sindicais, comitês de atingidos, assessorias técnicas, frentes amplas, setores progressistas da universidade, dentre outros sujeitos coletivos, têm pautado o enfrentamento às violências e violações que esse modelo e atividade econômico-produtiva geram.

O saqueio, a destruição ambiental, a violência e as mortes geradas pelo capital, neste caso em tela, pelas grandes empresas mineradoras, têm configurado um amplo contexto de enfrentamento por parte das comunidades e populações atingidas, o que vem conformando um internacionalismo das lutas sociais, políticas e ambientais que tensionam e confrontam as relações sociais e a sociabilidade engendrada pelo capitalismo na América Latina.

\section{A mineração extrativista na América Latina enquanto uma engrenagem do capitalismo dependente}

\author{
Entre estatais \\ E multinacionais, \\ Quantos ais!
}

(Carlos Drummond de Andrade)

O lugar relegado à América Latina na história do capitalismo é o lugar do saqueio, exploração, destruição ambiental, violência e morte. Para compreender as manifestações atuais de tal contexto, é válido recorrer a Marx (2013, p. 821), especialmente à clássica passagem onde afirma que

A descoberta das terras auríferas e argentíferas na América, o extermínio, a escravização e o soterramento da população nativa nas minas, o começo da conquista e saqueio das Índias Orientais, a transformação da África numa reserva para a caça comercial de peles-negras caracterizam a aurora da era da produção capitalista. 
Acerca da história da acumulação primitiva e do capitalismo, Marx prossegue afirmando que "a expropriação da terra que antes pertencia ao produtor rural, ao camponês, constitui a base de todo o processo. Sua história assume tonalidades distintas nos diversos países e percorre as várias fases em sucessão diversa e em diferentes épocas históricas (MARX, 2013, p. 787).

Tais processos são forjados pela violência. Nas palavras do autor "a violência é a parteira de toda sociedade velha que está prenhe de uma sociedade nova" (MARX, 2013, p. 821). Considerando tais premissas de surgimento, constituição e hegemonia deste modo de produção em âmbito mundial, temos o fato de que

O capitalismo, em sua fase imperialista, acentua sua tendência a apropriar-se de novos territórios e de novos mercados, em sua partilha do mundo, o que faz com que a mundialização, a partir dessa perspectiva, se situe no âmbito da fase imperialista do capitalismo, privilegiando a expansão do sistema mundial capitalista (OSÓRIO, 2012, p. 84).

Nessa perspectiva, “[...] o sistema mundial capitalista apresenta uma clara divisão internacional do trabalho, na qual as economias centrais concentraram seus esforços na produção industrial enquanto ao menos a América Latina especializou-se na produção de matérias-primas e alimentos (OSÓRIO, 2012, p. 83).

A partir de tais formulações, e direcionando a reflexão mais fortemente ao contexto da mineração extrativista na América Latina e no quadrilátero ferrífero (MG), temos, em plena fase imperialista do capitalismo, a expressiva perpetuação do saqueio, da exploração da força de trabalho, da violência e da destruição ambiental.

Acerca do modelo extrativo exportador da América Latina, Boron (2013, p. 10) afirma que "[...] la experiencia histórica latino-americana demuestra es que esse processo fue, como la acumulación originaria analizada por Karl Marx em El Capital, una secuencia de eventos que se desplegó 'chorreando sangre y barro por todos los poros"'. Na mesma esteira analítica e interpretativa, Seonae e Algranati (2013, p. 69) afirmam que "el modelo extractivo exportador se profundizó en estas regiones a sangre y fuego".

A história da mineração no Brasil tem seus primeiros momentos imbricados e impulsionados pela condição de escravização. Coelho et al. (2020, p. 103-104) afirmam que "uma máquina de moer gente foi a marca da exploração nas primeiras regiões mineradas no Brasil". A região do quadrilátero ferrífero carrega as violentas marcas desse processo histórico de exploração da força de trabalho de negros escravizados e de intensa extração de minérios e minerais. "Quando olhamos a história da mineração no Brasil da época colonial até os dias de hoje temos inúmeros episódios de genocídios, destruição ambiental, domínio à força dos territórios e dos habitantes que neles residiam e repressão à organização dos trabalhadores da mineração" (COELHO et al., 2020, p. 104).

Temos, portanto, que o capitalismo, enquanto sistema mundial e que se estrutura de modo heterogêneo no globo, estabelece padrões de conduta distintos ao longo dos períodos históricos, em que privilegia ramos e setores de investimentos, utiliza-se de meios de produção específicos e explora valores de uso para os mercados interno e/ou externo, tudo para a adequação das suas necessidades de reprodução (OSÓRIO, 2012).

Diante dos requerimentos da economia capitalista mundial e da divisão internacional do trabalho, os países latino-americanos, sob a égide do capitalismo dependente, são conformados à condição de fornecedores de matérias-primas e gêneros alimentícios e muito fortemente de transferência de valor via conformação de suas economias e processos produtivos fundamentados a partir da superexploração da força de trabalho e da dependência. Nas palavras de Marini (2005, p. 141), “[...] dependência entendida como uma relação de subordinação entre nações formalmente independentes, em cujo marco as relações de produção das nações subordinadas são modificadas ou recriadas para assegurar a reprodução ampliada da dependência."

Nessa mesma linha teórica, Osório (2012) argumenta que na América, a partir de 1970, se põe em curso um novo padrão exportador, cuja conformação tem vinculação com a crise capitalista do final da década de 1960, com as mudanças tecnológicas, com uma nova divisão internacional do trabalho e com o processo de mundialização da economia. Nesse sentido, a venda de mercadorias nos mercados mundiais é um fator fundamental para a vigência e viabilidade desse novo padrão de reprodução do capital, o exportador. "Em essência, o novo padrão exportador apoia-se sobre matérias-primas (agrícolas, minerais ou de energia) e em alimentos, com algum grau de processamento, assim como em bens industriais nos quais predomina a atividade de maquila e, em menor medida, a produção em si” (OSÓRIO, 2012, p. 116). 
Considerando a conformação assumida pelo capitalismo em âmbito mundial, ou seja, a dominação de alguns Estados-Nação sobre outros, o antagonismo cada vez mais agravado entre as classes sociais, as particularidades do capitalismo no continente latino-americano, em que a dependência é a sua configuração determinante, o mesmo autor afirma que "no mesmo período em que um padrão econômico voltado para os mercados externos está em curso e atinge importantes realizações, os salários e as condições gerais de trabalho e de vida da maioria da população da América Latina assistem a uma drástica precarização" (OSÓRIO, 2012, p. 122).

É a partir de tal compreensão que no item a seguir serão evidenciadas algumas das nuances e explicitações da superexploração da força de trabalho, dependência, violência e morte no contexto da mineração extrativista em Minas Gerais.

\title{
A mineração extrativista em Minas Gerais: o rastro de rejeitos e destruição
}

\author{
A divida interna. \\ A divida externa \\ A divida eterna. \\ (Carlos Drummond de Andrade)
}

A atividade produtiva da mineração em Minas Gerais, mais especificamente na região do quadrilátero ferrífero, a partir das décadas finais do século XX e nesta primeira década do século XXI, se conforma a partir de um novo padrão de reprodução do capital, o padrão exportador, em contexto de mundialização do capital e sob o domínio cada vez mais expressivo das economias/nações imperialistas.

Sob tais determinações, as atividades assumem o caráter extrativista e ganham relevância devido à sua ampliação e intensificação, consequentemente, aos elevados índices de superexploração da força de trabalho e destruição, violência e violações que geram. Essa situação se põe como uma constante nos diferentes países do continente latino-americano. É evidente, nesse contexto, o avanço do agronegócio, da extração de minérios e minerais, e da exploração de matrizes energéticas (SEOANE; ALGRANATI, 2013). Nesse sentido, por extrativismo podemos compreender

[...] aquellas actividades económicas que se basan en la explotación de biens comunes naturales que, sin ningún processamento o com alguno poco significativo, son comercializados em el mercado mundial. [...] se considera que el extractivismo remite a las actividades que utilizan o explotan bienes que son considerados no renovables como por ejemplo el petróleo, el gas o los minerales. (SEOANE; ALGRANATI, 2013, p. 24).

As atividades produtivas a partir de tal conformação são pautadas na superexploração da força de trabalho e na destruição ambiental, sob a lógica da dependência e subordinação econômica e política que o capitalismo pressupõe para a sua perpetuação enquanto modo de produção que se torna hegemônico no globo. Nesse sentido, é relevante assumir as formulações de Karl Marx (2013) em sua obra O Capital, quando afirma que a mercadoria força de trabalho é uma mercadoria especial, pois é a única que tem a capacidade de gerar mais valor, isto é, um valor superior ao que vale. $\mathrm{O}$ autor também argumenta que o valor da força de trabalho possui duas dimensões: o valor total e o valor diário, sendo o valor total da força de trabalho que determina o seu valor diário.

Assumindo tal premissa, os mecanismos de extração de trabalho excedente, e que "configuram um modo de produção fundado exclusivamente na maior exploração do trabalhador, e não no desenvolvimento de sua capacidade produtiva" (MARINI, 2005, p. 156), em economias que vivenciam a chamada troca desigual, são: "a intensificação do trabalho, a prolongação da jornada de trabalho e a expropriação de parte do trabalho necessário ao operário para repor sua força de trabalho" (MARINI, 2005, p. 156).

Esses mecanismos se expressam nos elevados índices de morte, adoecimentos e acidentes de trabalho, no pagamento de baixos salários e nos exaustivos turnos laborais a que os trabalhadores e trabalhadoras da mineração extrativista são submetidos. Fundamentalmente, estes são elementos presentes no cenário prérompimento/crime da barragem de Fundão em Mariana (MG), e que conformam uma máxima manifestação da dependência e da superexploração da força de trabalho no contexto da mineração extrativista no quadrilátero ferrífero de MG (BERTOLLO, 2017). 
Considerada como a atividade econômica que mais mata trabalhadores no Brasil, somente em 2016, quando a taxa nacional de óbitos no trabalho foi de 5,57 para cada grupo de 100 mil empregados formais, a mineração registrou uma taxa de 14,81 mortes, ou seja, as atividades do setor mineral matavam três vezes mais que a média dos outros setores. De acordo com os dados do Observatório de Saúde e Segurança do Trabalho do Ministério Público do Trabalho (OBSERVATÓRIO SST, 2020), nas mineradoras, no Brasil, foram 25.650 notificações de acidentes de trabalho, entre 2012 e 2018, sendo que uma parcela dessas vítimas teve que se aposentar por invalidez ou morreu. (COELHO et al., 2020, p. 125).

Osório (2012, p. 51) contribui para melhor compreendermos esse contexto de superexploração da força de trabalho quando afirma que

um salário insuficiente ou um processo de trabalho com sobredesgaste (seja pelo prolongamento da jornada laboral, seja pela intensificação do trabalho), que encurtem o tempo de vida útil e de vida total, constituem casos em que o capital está se apropriando hoje dos anos futuros de trabalho e de vida. Definitivamente, estamos diante de processos de exploração redobrada, na medida em que se viola o valor da força de trabalho. (OSÓRIO, 2012, p. 51, grifo do autor).

A produção/extração exacerbada de minério de ferro nas mineradoras do quadrilátero ferrífero, ultrapassando os limites físicos e morais da própria mercadoria força de trabalho, a fim de atender as demandas comerciais/ econômicas do mercado mundial, reafirma as premissas expostas por Marx (2013, p. 337-338)

[...] o capital transgride não apenas os limites morais da jornada de trabalho, mas também seus limites puramente físicos. [...] o capital não se importa com a duração de vida da força de trabalho. O que lhe interessa é única e exclusivamente o máximo de força de trabalho que pode ser posta em movimento numa jornada de trabalho. [...] A produção capitalista, que é essencialmente produção de mais-valor, sucção de mais-trabalho [...] produz o esgotamento e a morte prematuros da própria força de trabalho.

Nesse sentido, é possível afirmar que os rompimentos/crimes de barragens de rejeitos das mineradoras, enquanto ação com estreita vinculação e decorrentes da superexploração da força de trabalho e da apropriação/ extração exacerbada dos bens naturais comuns, são constantes e rotineiros na mineração extrativista operacionalizada no quadrilátero ferrífero de MG. Ressalta-se que neste território ocorreram rompimentos de barragens de rejeitos da mineração nos seguintes anos e municípios: 1986 - Itabirito; 2001 - Nova Lima; 2007 - Miraí (atingindo também o município de Muriaé); 2014 - Itabirito (OLIVEIRA, 2015). É evidente que esses rompimentos/crimes não ganharam expressiva repercussão em nível nacional e mundial, por mais que tenham desencadeado mortes e destruição ambiental.

Foram os recentes rompimentos da barragem de Fundão, em Mariana, no dia 05 de novembro de 2015, e da barragem Córrego do Feijão, em Brumadinho, no dia 25 de janeiro de 2019, que afloraram com mais força as denúncias e enfrentamentos por diferentes entidades e organizações de defesa dos direitos humanos e ambientais, apontaram para a necessária atuação de forma ampla e articulada entre movimentos sociais, entidades sindicais e demais sujeitos coletivos, e, principalmente, requisitaram a própria organização das comunidades direta e indiretamente atingidas.

Pode-se afirmar que esses últimos rompimentos criminosos portam e desnudam a historicidade secular violenta e criminosa que as empresas mineradoras assumem no processo produtivo da mineração desde os seus primórdios. Do ouro ao minério de ferro, do Brasil colônia ao Brasil Estado-Nação formalmente independente, da escravidão ao trabalho assalariado, o que esta singular região de MG vivenciou é marcado a sangre y fuego.

O rompimento/crime da barragem de Fundão, de propriedade das mineradoras Samarco Mineração, Vale S.A. e BHP Billiton,

despejou 43,7 milhões de metros cúbicos de rejeitos na bacia hidrográfica do rio Doce, deixando um lastro de vinte mortes entre moradores do distrito de Bento Rodrigues, que foi imediatamente atingido, e trabalhadores que estavam no canteiro de obras da barragem. A lama também destruiu e matou a fauna e a flora ao longo dos mais de 600 quilômetros de rios até chegar e adentrar o oceano no estado do Espírito Santo. Foram atingidos 36 municípios mineiros e 03 capixabas. (BERTOLLO; NOGUEIRA, p. 102). 
Em Brumadinho, o rompimento/crime da barragem da Mina Córrego do Feijão de propriedade da Vale S.A.

despejou cerca de treze milhões de metros cúbicos de rejeitos, tendo sido considerado o maior acidente de trabalho com perdas de vidas humanas do país. Foram causadas, imediatamente, cerca de 300 mortes de trabalhadores da mineradora que naquele momento cumpriam expediente e, também, de moradores e moradoras locais. [...] No que se refere aos danos ambientais, além de destruir fortemente o município de Brumadinho e o distrito de Córrego do Feijão, o rompimento/crime atingiu diretamente vários municípios ao longo da bacia do rio Paraopeba causando danos irreparáveis à fauna e flora. (BERTOLLO; NOGUEIRA, p. 102-103).

Em ambos os rompimentos criminosos o lastro de rejeitos atingiu áreas urbanas, áreas rurais, comunidades quilombolas, ribeirinhas e populações indígenas causando perdas materiais e imateriais irreparáveis. O processo de reparação e reconstrução dos distritos destruídos é moroso, está atrasado, é permeado por embates das populações direta e indiretamente atingidas e suas assessorias técnicas contra as mineradoras e Fundações criadas para conduzir os processos, que, se diga, são conduzidos de maneira muito facilmente questionável ética e resolutivamente. Nas palavras dos atingidos e movimentos sociais, tal contexto e a forma como é operacionalizado nada mais são do que "um crime que se renova".

Além desse contexto mais diretamente vinculado aos rompimentos criminosos, é expressiva a destruição causada cotidianamente pela mineração extrativista e sua forma de operacionalização sobre as comunidades. A poeira incessante, $\mathrm{o}$ barulho intenso, a água turva e contaminada que chega às torneiras das casas, o intenso tráfego de caminhões e trens de carga, a desapropriação forçada de comunidades inteiras sob a justificativa de elevação do risco de rompimento das barragens, a alocação precária em hotéis ou nas residências de familiares dessas populações desalojadas, a destruição da paisagem da região (montanhas, serras, picos, rios, cachoeiras, nascentes d'água, ruínas e monumentos históricos etc.), dentre outros impactos, têm historicamente causado adoecimentos físicos e mentais na população residente no entorno das minas e barragens de rejeitos ou em territórios visados para dar início à exploração mineral extrativista.

Também, a ofensiva sobre as lideranças locais, entre as quais as mulheres são protagonistas, tem aumentado significativamente. Calúnia, difamação, perseguição, ameaças diretas, racismo, machismo e sexismo são formas de violências e violações sofridas pelas lutadoras sociais na região do quadrilátero ferrífero em MG.

Por ser negra, mulher do alto do morro, já é uma invisibilidade, estou na luta já tem cinco anos. Imagina uma mulher preta do alto do morro militante? A empresa me fez uma proposta de sair da militância, de sair da frente das reuniões, se eu deixar de lutar pelo povo serei reconhecida como atingida e terei todos os direitos reconhecidos, inclusive o cartão emergencial retroativo. É dessa forma que as empresas atuam no território, se você é militante, se você tem coragem... a empresa é racista e machista, se você consegue ter espaço de fala você é ameaçada, tentam nos silenciar o tempo todo. Um funcionário da empresa em uma reunião de negociação, me mandou calar a boca. São essas coisas que uma atingida passa quando ela assume a posição de linha de frente (Atingida de Barra Longa). (JORGE et al. 2020, p. 149).

Coelho et al. (2020, p. 103) afirmam que "a história da mineração no Brasil é marcada por violências e resistências". Jorge et al. (2020, p. 150) afirmam que "o processo de criminalização se manifesta de forma mais direta pela ameaça, intimidação e perseguições que muitas vezes podem ser feitas pela própria empresa, desde que mais sutil, ou por 'capangas' ou mesmo milícias". É acerca das resistências a esse contexto que falaremos no item a seguir.

\title{
As resistências e lutas sociais possíveis e necessárias
}

\author{
Quantas toneladas exportamos \\ De ferro? \\ Quantas lágrimas disfarçamos \\ Sem berro? \\ (Carlos Drummond de Andrade)
}


Marini (2005, p. 141) afirma que "a consequência da dependência não pode ser, portanto, nada mais do que maior dependência, e sua superação supõe necessariamente a supressão das relações de produção nela envolvida." É nesse contexto que se inscrevem as resistências e lutas sociais possíveis e necessárias travadas por diferentes sujeitos coletivos no continente latino-americano frente ao padrão exportador de reprodução do capital, consequentemente também no contexto da mineração extrativista no quadrilátero ferrífero em MG.

A reafirmação e perpetuação da dependência pelo modelo extrativo exportador pressupõe e intensifica o saqueio dos bens naturais comuns, a superexploração da força de trabalho e a destruição ambiental. Requer

[...] necessariamente el uso de la violência, el fraude, la corrupción y el autoritarismo. Una trágica lista de asesinatos de líderes comunitários, acción de fuerzaas paramilitares, sanción de legislaciones repressivas, militarización social, emergência de um nuevo despotismo recorren los enclaves extractivistas en nuestra región. (SEOANE; ALGRANATI, 2013, p. 28).

O peso das cargas de minérios e minerais exportadas equivale ao secular peso da exploração, da destruição, das violências e violações deixadas neste chão e em suas gentes. A partir do exposto acerca do modo de produção capitalista e sua particularidade de conformação na América Latina, reitera-se que as experiências de lutas práticas e programáticas desencadeadas pelos sujeitos coletivos e setores populares no continente latinoamericano e no território em tela se desencadeiam a partir da perspectiva da luta de classes enquanto força motriz da história. As lutas sociais se forjam e se configuram a partir de classes sociais antagônicas, objetivando e assumindo a perspectiva de alcance e construção de um novo horizonte social em que a Emancipação Humana é condição estruturante, e que consequentemente pressupõe e abarca a requisição e a luta por um novo modelo de mineração, diferente deste requerido e assumido no modo de produção capitalista pelo modelo extrativo exportador, bem como por áreas livres de mineração.

Nesse sentido, é fundamental perceber o entendimento de que

[...] a emergência, o auge e o declínio de determinado padrão de reprodução do capital, assim como as condições para a emergência e o amadurecimento de um novo, com seu ciclo de auge e posterior declínio e crise. Em todos esses processos há razões econômicas que também são políticas. São projetos de classe de determinados setores do capital aqueles que se convertem em eixos de acumulação em cada caso, e são projetos de classe de outros setores do capital aqueles que ocupam lugares subordinados ou perdem. Tudo isso, por sua vez, tem consequências nas classes dominadas e em suas formas de existência. Existem projetos de reprodução do capital menos agressivos ao mundo do trabalho, ou em relação a alguns estratos específicos de tal mundo. Outros, no entanto, constituem projetos que agudizam a exploração e a exploração redobrada, gerando formas de capitalismo em que a barbárie tende a imperar acima da dimensão civilizatória que encarna. (OSÓRIO, 2012, p. 46).

Além das contradições e embates oriundos, decorrentes e mais fortemente vinculados à esfera da produção, não podemos desconsiderar os que ocorrem na esfera da reprodução social, uma vez que ambas as esferas e seus antagonismos conformam o todo dos conflitos classistas. Apontamos que são inúmeras e variadas as estratégias das mineradoras no sentido de apaziguar, cooptar e extinguir as lutas e resistências sociais, que abarcam o cunho ideológico e assumem fortemente um caráter repressivo/criminoso, em que a presença do Estado por meio dos aparatos político, financeiro, militar, judicial e moral é requerida de forma expressiva pelo capital. Seoane e Algranati (2013, p. 240) afirmam que "la lógica del despojo que caracteriza a la acumulación por despossesión del modelo extractivo exportador, lleva implícita, no como error sino como regla, la violência estatal y paraestatal".

Além desse caráter explícito de violências e violações, pressão e criminalismo, partindo de uma referência ideológica do capital, o argumento de que a atividade da mineração gera desenvolvimento econômico e progresso nos territórios em que ela já acontece, ou naqueles que apresentam potencial de operacionalização, vai se enraizando e se materializando nas práticas sociais, institucionais e nas condutas de ação de diferentes sujeitos, conformando o que Seoane e Algranati (2013, p. 240) conceituam como "gobernabilidad social del extractivismo". Nessa esteira, os autores explicitam que

La justificación del modelo extractivo exportador se sustenta habitualmente - tanto en los discursos corporativos como del funcionariado político y los comunicadores sociales - em el aporte aparentemente 
insustituible que dichas actividades realizan al crecimiento económico, al empleo y el desarrollo local y nacional. Esta formulación, em sus versiones mejor intencionadas, sirve para delimitar una cuestión ambiental y su afectación como una consecuencia no deseada pero inevitable, como um "daño colateral" negativo pero aceptable a la luz de los benefícios económicos-sociales obtenidos (SEOANE; ALGRANATI, 2013, p. 240).

Essas "lógicas simbólicas de constituición de territórios y pueblos sacrificables" (SEOANE; ALGRANATI, 2013, p. 241) estão presentes na realidade das comunidades e no cotidiano e vida das populações atingidas direta e indiretamente pela mineração extrativista em MG.

Para se consolidar nos territórios, as mineradoras apresentam a instalação do seu empreendimento como um fato inquestionável, como um retrato da realidade. A população, então, acaba se acostumando com a precariedade e com os impactos negativos do empreendimento, como se eles fossem inevitáveis - "um mal necessário". Desenhos de trens, barulho de suas buzinas e buracos nas montanhas e serras são naturalizados desde a infância nesses territórios atingidos pela mineração, o que ilustra, em partes, a situação de minériodependência. (JORGE et al., 2020, p. 134-135).

No enfrentamento a tal contexto, localizam-se as atuações de movimentos sociais, entidades sindicais, frentes amplas, comitês de atingidos, assessorias técnicas, dentre outros sujeitos coletivos. No caso em tela, destacamos a atuação do Movimento pela Soberania Popular na Mineração (MAM), do Movimento dos Atingidos por Barragens (MAB), do Sindicato Metabase Inconfidentes (SMI), da Frente Mineira de Luta das Atingidas e Atingidos pela Mineração em Minas Gerais (FLAMA), das equipes de assessoria técnica independentes que atuam diretamente com as populações e comunidades atingidas pelos rompimentos criminosos de Mariana e Brumadinho e de grupos de estudos, pesquisa e extensão ligados à Universidade Federal de Ouro Preto (UFOP), dentre outros.

A atuação articulada dos diferentes sujeitos sociais na região do quadrilátero ferrífero é histórica, no entanto, desde o rompimento/crime ocorrido em Mariana no ano de 2015 tais ações foram ganhando maior articulação e ganharam significativa ampliação, pois novos indivíduos e sujeitos se incorporaram às lutas e ao contexto de resistência ao atual modelo de mineração extrativista em vigência, que deixa para estas gentes e este chão apenas destruição ambiental e morte, situação que se reafirmou quando do rompimento/crime em Brumadinho no ano de 2019.

Destaca-se a importância da articulação das lutas nos países latino-americanos, uma vez que o modus operandi do capital sobre este chão é o mesmo. O internacionalismo das lutas e ações organizativas da classe trabalhadora, populações e comunidades atingidas pelas mineradoras forja-se na contestação aos imperativos do capital acerca da apropriação dos territórios, destruição ambiental e superexploração da força de trabalho, ou seja, ao padrão exportador de reprodução do capital.

No obstante, casi como una regla del poder, a cada tentativa de hegemonía suele contraponérsele al menos un acto de impugnación. Y en América Latina es factible hallar un múltiple y extendido repertorio de acción colectiva que ha refutado y hasta repelido al extractivismo minero (ESPINOZA, 2018, p. 54).

O mesmo autor apresenta um breve panorama das lutas e resistências travadas pelos grupos, movimentos e organizações que se põem no enfrentamento à mineração extrativista no continente latino-americano:

Para manifestar sus posturas, los individuos y grupos antiextractivistas han emprendido acciones diversas y en distintos espacios, tales como la organización de seminarios, talleres y foros, la realización de asambleas, la recolección de firmas, la publicación de desplegados, las marchas, los bloqueos carreteros, las clausuras simbólicas de minas, los plantones en sedes oficiales de distintos poderes públicos y embajadas, las pintas, las escenificaciones dramáticas, las huelgas de hambre, las declaratorias de municipios o territorios libres de minería (sobre todo en Argentina, El Salvador, Guatemala, Honduras, México y Uruguay), y las consultas comunitarias (en Argentina, Colombia, Ecuador, Guatemala y Perú), así como acciones más entroncadas en el ámbito institucional, como las audiencias públicas, los plebiscitos y los referéndums (de mayor uso en Argentina, Perú, Uruguay), las impugnaciones y las controversias jurídicas a códigos y artículos relacionados con la minería, así como la propuesta de leyes (ESPINOZA, 2018, p. 59). 
O que se evidencia na contemporaneidade é que sob os ditames imperialistas a América Latina figura como um território saqueado e explorado que cumpre um papel fundamental para a movimentação das engrenagens do mercado mundial. Assim, se as relações econômicas são transnacionalizadas entre países de capitalismo central e de capitalismo dependente, o enfrentamento aos conflitos e processos de exploração decorrentes dessa relação também possuem caráter internacionalista.

[...] el extractivismo minero en América Latina ha sido amplia y sistemáticamente increpado, refutado y hasta abolido. La acción colectiva antiextractivista ha sido relevante no sólo porque ha detenido un poco el avance de la minería a gran escala en América Latina, sino sobre todo por lo que sus impugnaciones han evidenciado. [...] las resonancias de la acción colectiva han ido más allá de los ámbitos económico, social y medioambiental pues los movimientos socioambientales han podido evidenciar que el extractivismo minero ha profundizado las asimetrías políticas por triplicado. (ESPINOZA, 2018, p. 64-65).

Inscrevemos as lutas e resistências travadas na região do quadrilátero ferrífero contra a mineração extrativista como parte das lutas que objetivam a superação do modo de produção capitalista. No contexto da luta de classes, as resistências se fazem enquanto processos contestatórios da exploração da força de trabalho, das opressões e da destruição ambiental, e desencadeiam os processos históricos vivenciados pelo gênero humano. "[...] entendemos que a luta dos atingidos pela mineração transnacional não se reduz à conquista do poder político. A luta de resistência à mineração aponta para a necessidade histórica de emancipação e transformação social" (IKEDA, 2020, p. 205).

\section{Considerações finais}

O modo de produção capitalista tem por fundamento a propriedade privada dos meios de produção e a exploração da força de trabalho, o que explicita interesses inconciliáveis entre as classes sociais fundamentais. É nesse contexto que a atividade da mineração extrativista se localiza, uma vez que requer a intervenção humana sobre a natureza. A América Latina e a região do quadrilátero ferrífero de MG figuram como territórios historicamente saqueados e explorados, e os rompimentos criminosos das barragens de Fundão e do Córrego do Feijão se inscrevem como pesadas cargas ao povo mineiro, à classe trabalhadora.

O padrão de reprodução do capital que se impõe ao continente e a esta singular região do País através da exportação de minérios e minerais, ao passo que produz e transfere valor às nações imperialistas e suas classes dominantes, deixa para este chão destruição ambiental e exploração da força de trabalho, o que conforma um cenário de violências, violações, opressões. O processo produtivo é pautado na superexploração da força de trabalho, que se estrutura basicamente a partir de jornadas de trabalho intensas e prolongadas, do pagamento de baixos salários, da terceirização, de elevados índices de adoecimento, acidentes de trabalho e mortes.

Além dessas manifestações da exploração sobre a força de trabalho diretamente empregada nas minas, o contexto de violência se amplia e atinge as comunidades e populações residentes nos arredores dos complexos produtivos. A expulsão da população de comunidades ocupadas secularmente tornou-se uma constante, é uma estratégia de avanço das mineradoras sobre o território. A criminalização das lutas e das lideranças se amplia ao passo da ampliação das articulações e resistências dos direta e indiretamente atingidos pela mineração extrativista.

Assim, as lutas sociais na América Latina e na região do quadrilátero ferrífero, enquanto resultantes da intensificação dos conflitos políticos, econômicos, sociais e ambientais causados pela exploração mineral, também são e expressam a força da classe trabalhadora no enfrentamento a tal contexto, seja ao modelo de processo produtivo imposto pelas mineradoras, seja à destruição ambiental desencadeada pelas mineradoras via rompimentos criminosos ou no cotidiano de operacionalização dessa atividade produtiva.

Nesse cenário as lutas são travadas e a região ocupa um lugar emblemático e historicamente relevante. $\mathrm{O}$ avanço das lutas sociais e resistências populares faz-se imprescindível. A classe trabalhadora e suas formas organizativas são a engrenagem que pulsa o tensionamento para a necessária transformação social, seja de modo de produção de mercadorias, seja de produção da vida e das relações sociais. Compreendendo que o capital é uma relação social, inscreve-se que os processos de luta e resistência seguem abertos na formulação de um horizonte social distinto deste sob os desígnios das classes dominantes e seus imperativos sobre os territórios, comunidades e bens naturais comuns. 


\section{Referências}

BERTOLLO, K. Mineração e superexploração da força de trabalho: análise a partir da realidade de Mariana-MG. 2017. Tese (doutorado) - Programa de Pós-graduação em Serviço Social, Universidade Federal de Santa Catarina, Florianópolis, 2017.

BERTOLLO, K.; NOGUEIRA, R. Aportes críticos sobre a mineração extrativista em Minas Gerais e sua relação com a universidade pública. In: MOASSAB, A.; VERRISSÍMO, C. (org.). Ecologia e Sociedade na América Latina. Caderno Sesunila, n. 3, Foz do Iguaçu, 2020. Disponível em: https://issuu.com/cadernosesunila/docs/03. Acesso em: 28 jan. 2021.

BORON, Atilio A. Prólogo. In: SEOANE, J.; TADDEI, E; ALGRANATI, C. Extractivismo, despojo y crisis climática: desafíos para los movimientos sociales y los proyectos emancipatórios de Nuestra América. Buenos Aires: Herramienta, El Colectivo, 2013. p. 9-15. COELHO, T. P. et al. O poder e a resistência dos movimentos populares e as alternativas ao modelo mineral brasileiro. In: ALVES, M. da S. et al. (org.). Mineração: realidades e resistências. São Paulo: Expressão popular, 2020. p. 103-130.

ESPINOZA, M. I. M. Repertorios de acción colectiva frente al extractivismo minero en América Latina. Andamios, México, v. 15, n. 37, 2018.

IKEDA, J. C. O. O Deus de ferro e a excomunhão da América Latina: Mineração transnacional, lutas e resistências sociais na Amazônia. 2020. Tese (doutorado) - Programa de Pós-graduação em Políticas Públicas, Universidade Federal do Maranhão, São Luís, 2020.

JORGE, D. P. et al. Poder, sedução e autopromoção das empresas de mineração em territórios atingidos por desastres criados em Fundão e no Córrego do Feijão. In: ALVES, M. da S. et al. (org.). Mineração: realidades e resistências. São Paulo: Expressão popular, 2020. p.131-159.

MARINI, R. M. Dialética da Dependência. In: TRASPADINI, R.; STEDILE, J. P. (org.). Ruy Mauro Marini: vida e obra. São Paulo: Expressão Popular, 2005. p. 137-180.

MARX, K. O Capital: crítica da economia política. Tomo I. São Paulo: Boitempo, 2013.

OLIVEIRA, N. Minas já sofreu com outros rompimentos de barragens. O Tempo, Belo Horizonte, 5 nov. 2015. Disponível em: https:// www.otempo.com.br/cidades/minas-ja-sofreu-com-outros-rompimentos-de-barragens-1.1159501. Acesso em: 14 jan. 2021.

OSÓRIO, J. Padrão de reprodução do capital: contribuições da teoria marxista da dependência. São Paulo: Boitempo, 2012.

SEOANE, J.; TADDEI, E.; ALGRANATI, C. Extractivismo, despojo y crisis climática: desafíos para los movimientos sociales y los proyectos emancipatórios de Nuestra América. Buenos Aires: Herramienta, El Colectivo, 2013.

UNIVERSIDADE FEDERAL DE OURO PRETO (UFOP). Quadrilátero ferrífero 2050. Disponível em: https://qfe2050.ufop.br/ municiipios-do-qfe. Acesso em: 20 jan. 2021.

\section{Nota}

1 O quadrilátero ferrífero é uma região do estado de Minas Gerais que compreende 34 municípios: Barão de Cocais, Belo Horizonte, Belo Vale, Betim, Brumadinho, Caeté, Catas Altas, Congonhas, Conselheiro Lafaiete, Ibirité, Igarapé, Itabira, Itabirito, Itatiaiaçu, Itaúna, Jeceaba, João Monlevade, Mariana, Mário Campos, Mateus Leme, Moeda, Nova Lima, Ouro Branco, Ouro Preto, Raposos, Rio Acima, Rio Manso, Rio Piracicaba, Sabará, Santa Bárbara, Santa Luzia, São Gonçalo do Rio Abaixo, São Joaquim de Bicas, Sarzedo (UNIVERSIDADE FEDERAL DE OURO PRETO, 2021).

\section{Kathiuça Bertollo}

kathiuca.bertollo@ufop.edu.br

Doutorado em Serviço Social pela Universidade Federal de Santa Catarina (UFSC)

Professora Adjunta do Departamento de Serviço Social da Universidade Federal de Ouro Preto (UFOP)

\section{UFOP}

Rua do Catete, n. 166, Centro. Mariana - MG - Brasil

CEP: $35.420-000$

Agradecimentos

Não se aplica.

Agência financiadora

Não se aplica.
Contribuições das autoras

Não se aplica.

Aprovação por Comitê de Ética

Não se aplica. 
Consentimento para publicação Consentimento pela autora.

\section{Conflito de interesses}

Não há conflito de interesses. 